\title{
Can Breastfeeding Solve Inequality? The Relative Mediating Impact of BREASTFEEDING AND Home ENVIRONMENT on Poverty Gaps in Canadian Child Cognitive Skills ${ }^{1}$
}

\author{
PhYLlis L.F. RiPPEYOUNG
}

\begin{abstract}
Research has clearly shown that there is a gap in the cognitive skills scores between children living in poverty and those who are not. Although sociologists have focused on the educational environment of the home as an explanation for this gap, breastfeeding advocates have suggested that breastfeeding could address these disparities. In this paper, I assess the relative potential of these factors for remediating poverty gaps in cognitive skills among Canadian four and five year olds using cycles 6-8 of the National Longitudinal Survey of Children and Youth. Breastfeeding and an educationally rich home environment both have significant positive impacts on child cognitive skills, however, only the latter reduced the cognitive skills gap between poor and non-poor children. Thus, policy efforts should focus on comprehensive antipoverty strategies and not rely on mother's infant feeding practices to address class based cognitive skills gaps.
\end{abstract} Key words: poverty, test score gaps, breastfeeding, NLSCY

Résumé: En mesurant les aptitudes cognitives des enfants, cette recherche montre clairement un écart entre les résultats obtenus chez les enfants issus de milieu défavorisé et les autres. Les sociologues étaient d'avis qu'un milieu familial favorisant l'éducation expliquait en partie cet écart mais les groupes qui plaident pour l'allaitement naturel ont suggéré qu'il était peut-être attribuable à la pratique ou non de l'allaitement naturel. Dans cet article, j'évalue dans quelle mesure ces deux facteurs peuvent effectivement remédier à cet écart entre les aptitudes cognitives des enfants issus de milieu pauvre et les autres et ce, auprès des enfants canadiens de 4 et 5 ans participant aux cycles 6 à 8 de l'Enquête longitudinale nationale sur les enfants et les jeunes (ELNEJ). Il ne fait aucun doute que ces facteurs, allaitement naturel et milieu familial favorisant l'éducation,

1. While the research and analysis are based on data from Statistics Canada, the opinions expressed do not represent the views of Statistics Canada. 
contribuent tous deux au développement des aptitudes cognitives chez l'enfant; toutefois, seul le second facteur réduit effectivement cet écart entre les enfants pauvres et les autres. Par conséquent, nos politiques doivent miser avant tout sur des stratégies globales de lutte contre la pauvreté et non sur les pratiques d'allaitement des mères pour réduire cet écart dû aux inégalités sociales.

Mots clés: milieu défavorisé; lacunes de note du test; l'allaitement naturel; ELNEJ

\section{INTRODUCTION}

$V /$ ithin the fields of social stratification, the sociology of education, 1 child development, and economics, there is clear evidence that poverty is negatively correlated with cognitive skills, test scores, and other measures of intellectual ability and academic achievement. However, researchers have not unpacked the full explanation for this (Guo and Harris 2000). Some argue that income alone provides the financial capital necessary for children to meet their growing needs (Smith et al. 1997). Others argue that higher incomes allow parents to provide a greater investment in children's cognitive growth, by doing things such as reading to their children and involving them in educationally enriched activities (Guo and Harris 2000; Mayer 1997).

One explanation for the class based gap in child cognitive skills that has not been fully explored is breastfeeding. Breastfeeding has the potential to explain at least part of these gaps considering the large body of literature claiming that breastfed babies score higher on IQ tests (Anderson et al. 1999; Kramer et al. 2008; Oddy et al. 2003), and that upper and middle class mothers are more likely to breastfeed (Dubois and Girard 2003). Additionally, public health officials have been putting increasing emphasis on rising rates of breastfeeding, particularly because of its purported ability to reduce health inequalities (Rippeyoung 2009; Wolf 2010).

To address this gap in the literature, I examined 3,521 Canadian children using the National Longitudinal Survey of Children and Youth (Cycles 6-8) to assess the relative mediating impacts of breastfeeding and home environment on poverty gaps in child IQ, as measured by the standardized scores of the Peabody Picture Vocabulary Test (PPVT) when they were four to five years old. Understanding the causes of these test score gaps is important because cognitive skills are related to a number of other measures of well-being. According to Haskins and Rouse (2005:2), "children who score poorly on tests of intellectual skills during the preschool years do less well in elementary and high school and are more likely to become teen parents, engage in criminal activities, 
suffer from unemployment, and become clinically depressed as adults." Thus, by uncovering ways in which these early disparities in academic achievement can be reduced, we can better address a number of interrelated social problems throughout the life course.

\section{REVIEW OF THE LitERATURE}

\section{Income and Cognitive Skills Gaps}

Income has been clearly shown to have a positive impact on test scores, both when measured in terms of poverty (e.g., poor or not poor) or in terms of income (e.g., on a scale) (Guo and Harris 2000; Janus and Duku 2007; Phipps and Curtis 2000). For instance, Phipps and Curtis (2000) found that depending on how poverty is measured, poor children score between 3.154-4.586 points lower than children who are not poor on the PPVT using the first cycle of the NLSCY.

Smith et al. (1997) examined the role of income and poverty on a number of achievement and intelligence tests in the United States. Using both the Infant Health and Development Program (IHDP) data on low birth weight 5 year olds and the Children of the National Longitudinal Survey of Youth (C-NLSY) in the United States, they found that when looking at mean differences on a variety of intelligence, achievement, and verbal ability tests (the Bayley Scales, the Stanford-Binet IQ test, the Peabody Picture Vocabulary Test-Revised [used in this analysis], Peabody Individual Achievement Test, and the Wechsler Preschool and Primary Scale of Intelligence), poverty (measured by income to needs and the duration of poverty) has a consistently negative effect on children's cognitive achievement. They also found that the 2-7 year olds who were "very poor" scored 7-12 points lower than "near-poor" children. They interpret this to mean that increasing incomes to near-poor levels among the very poor could have a dramatic impact on children's cognitive scores.

\section{Explaining the Poverty/Income Gap}

Despite the clear correlation between poverty and cognitive skills, the question of why these disparities exist has not been settled (Yeung et al. 2002). If the reason for the disparities is simply a lack of income then solutions should include increasing income transfers. However, if the disparities are due to other factors correlated with income, such as family size, parenting styles, or health, then policy makers would be better served addressing those issues (Phipps and Curtis 2000). 
The main explanation of why poor children have lower test scores is known as the investment model. According to Conger et al. (2010:694), the investment model "proposes that families with greater economic resources are able to make significant investments in the development of their children, whereas more disadvantaged families must invest more in immediate family needs." Thus, families with higher incomes can afford to enrol their children in activities that stimulate growth and they have the time to read to their children or engage in other cognitively stimulating activities.

There is much support for the investment model in the literature (Gershoff et al. 2007; Guo and Harris 2000; Kiernan and Huerta 2008; Lugo-Gil and Tamis-LeMonda 2008; Yeung et al. 2002). Yeung et al. (2002) found, in their analysis of the Panel Study of Income Dynamics (PSID) in the US, that cognitively stimulating material in the home was a significant mediator of income gaps in the cognitive skills of children who were 3-5 years old in 1997. Similarly, Lugo-Gil and Tamis-LeMonda (2008) found that among low-income children, parenting quality, as measured by maternal sensitivity, positive regard, and cognitive stimulation, completely mediated the effect of family economic resources on cognitive performance at 14, 24, and 36 months of age.

Mayer (1997) focuses not only on the investments, but argues that such investments are a result of parents' orientations to such activities. She analyzed the NLSY data and the PSID and found that parenting activities such as reading to one's child or taking them to museums are highly related to children's success, but the amount of money a parent has is unrelated to how much they perform those activities. Rather, she argues that when a parent actually enjoys reading to his or her child, for example, that parent will engage in the kinds of parenting behaviours that lead to better outcomes.

Finally, parental education also plays an important role in povertybased cognitive skills gaps. As Conger, et al. (2010) point out, research examining these gaps has tended to lump education in with income and occupation either conceptually or statistically in a scale of socioeconomic status or family resources. They point out that education can determine both income and occupational prestige and "may act as an important personal resource that buffers against the potentially damaging impacts of reductions in income during downturns in the economy" (2010:669). Higher educational levels may also increase parents' knowledge of the importance of engaging in cognitively stimulating activities. Thus, assessing the unique effects of education is important in teasing out what is driving the poverty-based cognitive skills gap. 
In summary, based on their reported findings, Smith et al. (1997) argue that raising family incomes to near-poor levels, increasing mothers' educational levels, and implementing policies that encourage poor parents to read more to their children will raise their children's cognitive scores. Since poor families have significantly lower levels of all of these resources, increasing them for the poor will reduce class-based gaps. However, still not entirely clear is whether there are other means that would reduce these disparities further.

\section{Breastfeeding and Cognitive Skills}

One area that has received almost no attention among stratification scholars is infant nutrition. Research has consistently demonstrated a positive effect of breastfeeding on child health outcomes, as evidenced by its promotion by Health Canada (2005), the Public Health Agency of Canada (2009), and the World Health Organization (2003). One contentious argument in favour of breastfeeding is that the act of breastfeeding leads children to have higher cognitive skills (IQ) (Health Canada 2005).

There is clear evidence in the literature that breastfeeding is positively correlated with IQ. Some argue that this is due to the breastfeeding and/or the human milk itself (Anderson, et al. 1999; Gómez-Sanchiz et al. 2004; Kramer et al. 2008; Mortensen et al. 2002; Oddy et al. 2003). Others argue that the correlation is spurious since breastfeeding is highly correlated with high IQs in mothers; not only is IQ highly heritable (Dickens 2005), but also mothers with high IQs tend to create a more cognitively stimulating environment for their children (Der et al. 2006; Gibson-Davis and Brooks-Gunn 2006; Jacobson et al. 1999).

Those who argue that breastfeeding per se has an impact on child IQ have tended to carry out studies that controlled for a number of potential covariates and most found that the longer the baby was breastfed the larger the impact (Anderson et al. 1999; Gómez-Sanchiz et al. 2004; Mortensen et al. 2002; Oddy et al. 2003). One study that claims to find more support than most epidemiological studies is the Promotion of Breastfeeding Intervention (PROBIT) Study Group (Kramer et al. 2008). Examining babies born in Belarus, the researchers randomly assigned hospitals to carry out the practices of the Baby Friendly Hospital Initiative. ${ }^{2}$ The researchers found that those babies born in the treatment group had higher IQs than those born in the control group. However, there were both breast feeders and formula feeders in both the

2. A concept developed by UNICEF and the World Health Organization, a hospital can be deemed "Baby Friendly" "when it does not accept free or low-cost breast milk substitutes, feeding bottles or teats, and has implemented 10 specific steps to support successful breastfeeding" (UNICEF 2011). 
test and control groups, the only treatment was whether or not the hospital was "baby friendly" and mothers received greater encouragement and support with breastfeeding. Another study assessed the impact of breastfeeding duration on IQ in Brazil where breastfeeding is not linked to socioeconomic status and found that the longer duration of breastfeeding, the higher the IQ of the children (Brion et al. 2011); however this study did not control for mother's IQ.

A number of studies have found that when mother's IQ is included, the effect of breastfeeding goes away (Der et al. 2006; Gibson-Davis and Brooks-Gunn 2006; Jacobson et al. 1999; Zhou et al. 2007). The most compelling evidence for this is a study by Der et al. (2006) assessing the relationship between breastfeeding and IQ, controlling for the mother's IQ. They compared sibling pairs and carried out a meta-analysis of 73 studies that looked at the relationship between breastfeeding and IQ. Overall, they found that maternal intelligence can explain most of the association between breastfeeding and child intelligence, but that the

level of cognitive stimulation at home, mother's educational attainment and age at the birth of the child, child's birth order, and family financial hardship all have independent effects. In fully adjusted analyses, the advantage of breast feeding was small and not significant. (Der et al. 2006:5)

Thus, what matters may not be breastfeeding, but rather a rich educational environment provided by intelligent mothers, which is correlated with both breastfeeding and child IQ. However, this study also was not definitive, as there was no measure of the dose of breast milk that was given (i.e., whether children were exclusively breastfed or were fed supplemental formula) and the average duration of breastfeeding was half that of the recommended duration. Some have argued that if the subjects had exclusively breastfed for a longer duration, the effect of breastfeeding on IQ would have been significant even when controlling for mother's IQ (Massachusetts Breastfeeding Coalition 2006).

Although there is no consensus in the scientific community as to whether breastfeeding per se leads to cognitive gains in children, those advocating for breastfeeding tend to argue that breastfeeding has a positive impact on IQ (e.g., Health Canada 2005; La Leche League International [LLLI] 2006; Mason and Roholt 2006; Public Health Agency of Canada 2009). For instance, according to the Public Health Agency of Canada (2009:3), the number two "great reason to breastfeed your baby" is "Brain Power," because "there is strong evidence that children who were breastfed score higher on IQ tests, as well as on teacher ratings of their academic performance." 
Further, the claim is made that by getting more women to breastfeed, health inequalities in general can be addressed. In her editorial "The eradication of poverty one child at a time through breastfeeding," Ruth Lawrence (2007:193), a founder of the Academy of Breastfeeding Medicine, argues that "human milk not only supports ideal physical growth for the infant but is especially important for the ideal growth of the brain." Breastfeeding is not only argued to remediate health disparities (including brain growth) but also to have the capacity to eliminate poverty, as indicated by her title.

Public health researchers Dubois and Girard (2003) make similar arguments in their longitudinal study of inequalities in infant feeding in Quebec. In their study, they examine the relationship between socioeconomic status and breastfeeding rates. Although, their study examines only class based differences in rates of feeding and they have no measures of health or cognitive skills, they nonetheless conclude that:

Breast-feeding and nutrition could be related with different health and cognitive outcomes in childhood and later in life. Consequently, social disparities of diet in infancy could play a role in the development of social and health inequalities more broadly observed at the population level. Intervention to improve adherence to breast-feeding and nutrition recommendations in infancy should be prioritised. (2003:782, emphasis mine)

Dubois and Girard (2003) find evidence for a class based gap in infant feeding, and because other research has shown benefits of infant feeding for health and cognitive skills, they assume that breastfeeding would reduce these gaps and should therefore be prioritized.

\section{This Study}

Despite pronouncements that breastfeeding can reduce class inequalities in children's cognitive skills this has not been clearly demonstrated in the literature. Therefore, in this study, I assess two main arguments: the "breastfeeding advocate" argument and the "spurious effect" argument. The breastfeeding advocate argument indicates that breastfeeding itself can reduce poverty gaps in cognitive skills because breastfeeding is positively correlated with cognitive skills and research has shown lower rates of breastfeeding among the poor. The "spurious effect" argument posits that breastfeeding and poverty are both correlated with a third factor, a rich educational home environment, which means that the effect of breastfeeding is spurious and will, therefore, not reduce poverty-based gaps in cognitive skills. To assess these arguments, I analyzed a sample of 3,521 Canadian children born in 2004 using the National Longitudinal Survey of Children and Youth (NLSCY). 


\section{Data, Measures, and Method}

\section{Data}

The data used for this analysis were the three most recent cycles, 6-8, of the NLSCY, a prospective, longitudinal nationally representative study of Canadian children. The data include measures of breastfeeding, cognitive skills, and other potentially important confounding factors, as will be discussed below. Because the data are longitudinal, one can examine how a practice carried out in the first year of life can affect later outcomes at ages $4-5$.

Based on the Labour Force Survey as the sampling frame, the Early Child Development cohort of the NLSCY was first sampled in 1994, and then every two years thereafter. Each year new cohorts of children were added, while the original cohort was also tracked. The most recent cohort that would allow the addressing of these questions was cycle 6 in 2004 2005, with a target population of children aged 0-11 in Canada's ten provinces, excluding those in institutions, on Indian reserves, those fulltime in the armed forces, and in some remote areas (Statistics Canada 2006). The initial sample at cycle 6 included 26,000 children (including nonrespondents), but only those who were babies in the new cohort in cycle 6 were part of the sample in these analyses, reducing the sample to 3,521 children. All the children in this subsample were between 0-1 year old in 2004-2005, 2-3 years old in 2006-2007, and 4-5 years old in 2008-2009. Also eliminated were any children missing a value for the PPVT test, which dropped the sample size to 2,436 children (or $68 \%$ of the cycle 6 infant cohort). After carrying out listwise deletion on all the independent variables, the final sample size was 2,219, which was $91 \%$ of the cases who had scores on the dependent variable and were $0-1$ year old in Cycle 6.

\section{Variables}

The dependent variable in this analysis is the standardized score for the Peabody Picture Vocabulary Test-Revised (PPVT), taken when the children were 4 or 5 years old in cycle 8 . The PPVT is a commonly used measure of child vocabulary used to assess verbal IQ, by assessing how well a child respondent can point to a picture of a word that matches a word read by an interviewer (Statistics Canada 2008). For these analyses, the standardized scores, which adjust the raw scores for age, are used.

The main independent variable used in this analysis is poverty, based on Statistics Canada's Low-Income Cut-offs (LICO's) as they are the most common measure of poverty used in Canada (Phipps and Curtis 2000). If families spend $20 \%$ more of their income than other Canadian 
families to purchase necessities, they are considered to be low-income (Phipps and Curtis 2000). To assess a more permanent measure of poverty so that no one year could over- or under-represent the family poverty levels, I averaged the respondent's LICO scores for the three years of the study. I then recoded the values to create three dummy variables, the first category representing the poor were those who scored below a 1 on average, which represents the Low Income Cut-Off. Those who score, on average, up to 1 unit above the Low Income Cut-Off (i.e., between 1-1.999) were recoded as near-poor, and those who scored above that (i.e., 2 or higher) were coded as non-poor.

To assess breastfeeding status, I combined the item indicating whether the child was ever breastfed, even if for only a very short time with the item assessing how long the child was breastfed (for those who did), using cycles 6 and 7 when the infants were $0-2$ years old. These were then recoded to create a series of 4 dummy variables coded as: never breastfed, breastfed for less than 3 months, breastfed between 3-6 months, and breastfed for longer than 6 months. In all models, never breastfed is the omitted category.

To assess an educationally rich home environment, four variables were included. The first variable assessed child involvement in cognitively stimulating activities at cycle 8 and was derived by summing the total number of the following activities the child was involved in: nursery school or preschool; play group; drop-in centre; parent and child lessons or program; and library story time or other reading program or book club. The maximum possible score was a 5; the higher the score, the more activities parents involved their children in.

The second was a measure of how often either of the parents reads aloud to the child or listens to the child read or try to read at cycle 8 . This variable was coded so that 1 indicates rarely or never, 2 indicates a few times a month, 3 indicates once a week, 4 indicates a few times a week, and 5 indicates daily. Although the variable is an ordinal variable, it was treated as an interval variable in the analysis, and is to be interpreted as a one unit increase in reading will lead to an X unit increase in PPVT scores.

The third variable is a measure of positive parenting, measured when the children were $0-1$ year old. This scale variable was created by Statistics Canada and derived from five variables assessing how often the person most knowledgeable (PMK) praises the child, talks or plays with the child for fun for at least 5 minutes, laughs with the child, does something special that the child enjoys, or plays games with the child. As each item is a scale from $1-5$, the overall positive parenting scale has a possible range from 1-20, although most scores range from 10-20. 
Finally, the education attained by cycle 8 of the PMK about the child, typically the mother, was included. Education was measured through a series of dummy variables including: less than high school, high school diploma, some university or college, university degree, and other education. In all cases, university degree was omitted as that was the largest individual category.

A number of demographic controls were also included to address possible omitted variable bias. First included was whether the child is female, as female children have been shown to score higher on some cognitive skills tests (Dezoete et al. 2003). Second, the age of the mother when the child was born was incorporated as Der et al. (2006) found that was correlated with both child IQ and breastfeeding. Further, I included whether the PMK is employed in a professional occupation, since much research has shown that those in professional occupations are more likely to breastfeed their children for longer durations (Kimbro 2006). The PMK was coded as 1 for professional if she or he worked in a professional occupation in business or finance; natural and applied sciences and related occupations; professional occupations in health, nurse supervisors, and registered nurses; occupations in social science, government, and religion; and teachers and professors. All other professions or those who were unemployed were coded as 0 for professional. To control for family structure at cycle 8 , a series of dummy variables for marital status were incorporated into the analysis, including: married (omitted category), common-law, widowed/separated/divorced, and single. The number of siblings was included as an interval variable, as was a dummy for whether there were one or two parents in the household. Finally, to control for ill health at birth, there were two dummy variables to assess if the child was premature or low birth weight, and a measure assessing the qualitative health of the child on a scale from 1-5 with 1 indicating poor health and 5 indicating excellent health.

\section{Method}

The data were analyzed in the software package STATA and all estimates were weighted using the longitudinal weights and bootstrapping to address the complex survey design. To assess whether breastfeeding can mediate the poverty gap in child cognitive skills, I first calculated descriptive statistics for the entire sample, broken down by poverty classification (i.e., poor, near-poor, non-poor). I then carried out multiple t-tests to see if there were statistically significant differences between the three groups.

I followed the descriptive statistics by carrying out a series of ordinary least squares (OLS) regression models. A significant coefficient on 
the poverty and near poverty variables will indicate if there is a relationship between poverty and PPVT scores. By introducing a series of variables, we can see how the poverty coefficients change based on those factors. If the poverty coefficient becomes smaller with the introduction of breastfeeding, especially if it shifts to nonsignificance, this indicates that breastfeeding mediates (or helps to explain) the effect of income on test scores. We also can compare whether the poverty gap is diminished more with the introduction of breastfeeding variables or the educational environment in the home variables.

\section{Results}

\section{Descriptive Statistics}

Consistent with past research, the descriptive statistics establish that there are test score gaps based on poverty status. As shown in Table 1 , of children born in 2006, $11.97 \%$ were poor on average for the first 4-5 years of their lives, compared with $32.65 \%$ who were near poor and $55.38 \%$ who were non-poor. Of those who were poor, the average PPVT test score was 94.60 , compared with 98.44 for the near-poor and 104.38 for the non-poor. Each of the differences on PPVT test scores was statistically significantly different from each other at the $\mathrm{p}<.05$ level.

Overall, $12.69 \%$ of the infants born in 2006 were not breastfed, $20.83 \%$ were breastfed less than 3 months, $20.57 \%$ were breastfed between 3-6 months, and 45.9\% were breastfed longer than 6 months. This is slightly lower than what Chalmers et al. (2009) found in their study using data collected by Statistics Canada on behalf of the Public Health Agency of Canada. They found that across Canada 9.7\% of babies born in 2006 were never breastfed and $53.9 \%$ were breastfed at least 6 months. There were no statistically significant differences at the $\mathrm{p}<.05$ level between the three groups in their rates of breastfeeding.

The average number of educational activities that the children participated in when they were 4-5 years old was .64 and there were significant differences $(\mathrm{p}<.05)$ between the non-poor, near-poor, and poor, with $.71, .57$, and .48 activities respectively. Across poverty categories parents read to their children at least a few times a week, although the near-poor read to their children less frequently than the non-poor. There are clear differences in education between the non-poor and the other two poverty groups. Although $17.68 \%$ of the poor had less than a high school diploma, only $2.66 \%$ of the non-poor and $7.14 \%$ of the near-poor had not completed high school. There were statistically significant differences between all three groups in their rates of attaining a postsecond- 
Table 1. Descriptive Statistics (NLSCY, Cycles 6-8, 2004-2008)

\begin{tabular}{|c|c|c|c|c|}
\hline & All & Poor & Near-Poor & $\begin{array}{c}\text { Non-Poo } \\
10438\end{array}$ \\
\hline Cognitive Skills (PPVT) & 101.27 & $94.60^{\mathrm{a}, \mathrm{b}}$ & $98.44^{\mathrm{b}}$ & \\
\hline \multicolumn{5}{|l|}{ Income/Poverty } \\
\hline Poor & $11.97 \%$ & & & \\
\hline Near-poor & $32.65 \%$ & & & \\
\hline Not poor & $55.38 \%$ & & & \\
\hline Average income over 3 cycles & $\$ 79,893.41$ & $\$ 28,139.48^{\mathrm{a}, \mathrm{b}}$ & $\$ 53,012.24^{\mathrm{b}}$ & $\$ 106,928$. \\
\hline \multicolumn{5}{|l|}{ Breastfeeding Status } \\
\hline Never breastfed & $12.69 \%$ & $15.02 \%$ & $14.81 \%$ & $10.94 \%$ \\
\hline Breastfed less than 3 months & $20.83 \%$ & $29.55 \%$ & $19.10 \%$ & $19.97 \%$ \\
\hline Breastfed 3-6 months & $20.57 \%$ & $16.72 \%$ & $22.15 \%$ & $20.46 \%$ \\
\hline Breastfed longer than 6 months & $45.91 \%$ & $38.71 \%$ & $43.94 \%$ & $48.62 \%$ \\
\hline \multicolumn{5}{|l|}{$\begin{array}{l}\text { Educational Environment in the } \\
\text { Home }\end{array}$} \\
\hline $\begin{array}{l}\text { Number of educational activities } \\
\text { at age 4-5 }\end{array}$ & .64 & $.48^{\mathrm{b}}$ & $.57^{\mathrm{b}}$ & .71 \\
\hline $\begin{array}{l}\text { How often read to child at age } 4-5 \\
\text { (scale from } 1-5 \text { ) }\end{array}$ & 4.41 & 4.33 & $4.31^{\mathrm{b}}$ & 4.49 \\
\hline Positive parenting & 17.87 & 17.44 & 17.81 & 18.01 \\
\hline $\begin{array}{l}\text { Less than high school, cycle } 8 \\
\text { (PMK) }\end{array}$ & $5.92 \%$ & $17.68 \% \%^{\mathrm{a}, \mathrm{b}}$ & $7.14 \%^{\mathrm{b}}$ & $2.66 \%$ \\
\hline $\begin{array}{l}\text { High school Diploma, cycle } 8 \\
\text { (PMK) }\end{array}$ & $12.65 \%$ & $25.71 \%{ }^{\mathrm{b}}$ & $17.86 \%{ }^{\mathrm{b}}$ & $6.75 \%$ \\
\hline $\begin{array}{l}\text { Some postsecondary education, } \\
\text { cycle } 8 \text { (PMK) }\end{array}$ & $12.32 \%$ & $15.39 \%^{\mathrm{b}}$ & $16.19 \%^{\mathrm{b}}$ & $9.37 \%$ \\
\hline $\begin{array}{l}\text { Postsecondary degree(S), cycle } 8 \\
\text { (PMK) }\end{array}$ & $68.11 \%$ & $39.73 \% \mathrm{o}^{\mathrm{a}, \mathrm{b}}$ & $57.51 \%{ }^{\mathrm{b}}$ & $80.49 \%$ \\
\hline Other education, cycle 8 (PMK) & $1.01 \%$ & $1.49 \%$ & $1.31 \%$ & $0.73 \%$ \\
\hline \multicolumn{5}{|l|}{ Controls } \\
\hline $\begin{array}{l}\text { Professional occupation, cycle } 8 \\
\text { (PMK) }\end{array}$ & $28.52 \%$ & $10.40 \%^{\mathrm{b}}$ & $19.53 \%^{\mathrm{b}}$ & $37.73 \%$ \\
\hline Female child & $48.75 \%$ & $44.50 \%$ & $45.86 \%$ & $51.37 \%$ \\
\hline Age of mother at birth of child & 29.66 & $26.84^{\mathrm{ab}}$ & $29.08^{b}$ & 30.60 \\
\hline Number of siblings, cycle 8 & 1.31 & $1.44^{\mathrm{b}}$ & $1.40^{\mathrm{b}}$ & 1.23 \\
\hline Married, cycle 8 (PMK) & $71.07 \%$ & $35.77 \%$ ab & $66.62 \%{ }^{\mathrm{b}}$ & 81.27 \\
\hline Common-law, cycle 8 (PMK) & $17.75 \%$ & $16.75 \%$ & $20.89 \%$ & 16.115 \\
\hline $\begin{array}{l}\text { Widowed/separated/divorced, } \\
\text { cycle } 8 \text { (PMK) }\end{array}$ & $4.65 \%$ & $19.04 \% \mathrm{o}^{\mathrm{ab}}$ & $4.83 \%^{\mathrm{b}}$ & 1.44 \\
\hline Single, cycle 8 (PMK) & 6.555 & $28.44 \% \mathrm{o}^{\mathrm{ab}}$ & $7.66 \%{ }^{\mathrm{b}}$ & $1.17 \%$ \\
\hline $\begin{array}{l}\text { Two parents in the household, } \\
\text { cycle } 8\end{array}$ & $89.61 \%$ & $61.60 \%^{\mathrm{ab}}$ & $87.84 \%{ }^{\mathrm{b}}$ & $96.70 \%$ \\
\hline $\begin{array}{l}\text { One parent in the household, } \\
\text { cycle } 8\end{array}$ & $10.39 \%$ & $38.40 \% \mathrm{o}^{\mathrm{a}, \mathrm{b}}$ & $12.16^{\mathrm{b}}$ & $3.30 \%$ \\
\hline Premature birth & $18.47 \%$ & $16.51 \%$ & $24.12 \%$ & $15.56 \%$ \\
\hline Low birth weight & $7.09 \%$ & $9.49 \%$ & $6.87 \%$ & $6.71 \%$ \\
\hline Health at birth (Scale From 1-5) & 4.52 & $4.36^{\mathrm{a}}$ & 4.58 & 4.52 \\
\hline & 2,219 & 215 & 722 & 1,282 \\
\hline Population $\mathrm{N}=$ & 411,644 & 49,265 & 134,417 & 227,962 \\
\hline
\end{tabular}

NOTE: The data are weighted.

PMK refers to person most knowledgeable about the child, typically the mother.

a Significantly different from near-poor at $\mathrm{p}<.05$

${ }^{\mathrm{b}}$ Significantly different from non-poor at $\mathrm{p}<.05$ 
ary degree $-39.76 \%$ of the poor had a postsecondary degree, compared with $57.51 \%$ of the near-poor, and $80.49 \%$ of the non-poor.

Further, $28.52 \%$ of PMKs were in professional occupations by Cycle 8 . There were significant differences across all three groups with the poor having the lowest rates $(10.40 \%)$, followed by the near-poor $(19.53 \%)$, then the non-poor $(37.73 \%)$. There were no significant differences between the groups in terms of the gender of the children; overall $48.75 \%$ of the children born in 2006 were female. There were, however, differences between all of the groups in the ages at which the mothers had their infants. The overall average age at birth of mothers was 29.66 years old, for the poor 26.84 years, the near-poor 29.08 years, and for the non-poor 30.60 years. The non-poor had statistically significantly fewer siblings than the near-poor or the poor, at $1.23,1.40$, and 1.44 average siblings, respectively. The non-poor were also more likely to be married $(81.27 \%)$ than the near-poor $(66.61 \%)$ or the poor $(35.77 \%)$, and the difference between the near-poor and the non-poor was statistically significant as well. The rates of having one parent at home was also statistically significant between all three groups: $38.40 \%$ of the poor, $12.16 \%$ of the near poor, and $3.30 \%$ of the non-poor had only one parent in their household. In terms of the health of the children at birth, $18.47 \%$ of the children were born prematurely, $7.09 \%$ were low birth weight, and the mean for child health was 4.52 units, which was between very good and excellent health. There were no statistically significant differences in the rates of premature birth, low birth weight, or health at birth between the three groups.

\section{OLS Regression Models}

Examining model 1 in Table 2, we see that the poor score 9.773 points and the near-poor score 5.933 points lower than the non-poor. The differences between the poor and the near-poor are statistically significantly different. Poverty explains $5.4 \%$ of the variance in cognitive scores, which is not a substantial amount. Model 2 includes the addition of the control variables which reduce the poverty gap by 2.887 points and the near-poverty gap by 1.327 points and increases the $\mathrm{R}^{2}$ to $8.6 \%$. Only the number of siblings and having a professional occupation are statistically significant predictors of cognitive skills and are therefore likely the factors reducing the poverty test score gap.

From Model 3, we see that breastfeeding longer than six months has a statistically significant positive impact on cognitive scores controlling for demographics and poverty status. However, with the addition of these variables, the coefficients for poor and near-poor children shift only an 
Table 2. OLS Regression Models Predicting Peabody Picture Vocabulary Test Scores (PPVT)

Poor

Near-poor

Professional occupation

Female child

Siblings

Common-law

Widow/separated/divorced

Single

One parent

Age of mother at birth of child

Premature birth

Low birth weight

Health at birth

Breastfed less than 3 months

Breastfed 3-6 months

Breastfed longer than 6 months

Number of educational activities at age $4-5$

How often read to child at age 4-5 (scale from 1-5)

Positive parenting

Less than high school (PMK)

High school diploma (PMK)

Some postsecondary education (PMK)

Other education (PMK)

Constant

$\mathrm{R}^{2}$

Sample N=2,219; Population N=411,644; NOTE: Weighted coefficients (standard errors are in parenthesis); $* x \leq .05 ; * * p \leq .01 ; * * p \leq .001$ (two-tailed tests)

\begin{tabular}{|c|c|c|c|c|}
\hline Model 1 & Model 2 & Model 3 & Model 4 & Model 5 \\
\hline $\begin{array}{l}-9.773^{* * * *} \\
(1.779)\end{array}$ & $\begin{array}{l}-6.886^{* *} \\
(2.026)\end{array}$ & $\begin{array}{l}-7.123^{* * *} \\
(1.983)\end{array}$ & $\begin{array}{l}-5.100^{*} \\
(2.024)\end{array}$ & $\begin{array}{l}-5.437^{* *} \\
(1.982)\end{array}$ \\
\hline $\begin{array}{l}-5.933^{* * *} \\
(1.121)\end{array}$ & $\begin{array}{l}-4.606^{* * *} \\
(1.172)\end{array}$ & $\begin{array}{l}-4.608^{* * *} \\
(1.145) \\
\text { Controls }\end{array}$ & $\begin{array}{l}-3.590^{* * *} \\
(1.113)\end{array}$ & $\begin{array}{l}-3.693^{\text {*** }} \\
(1.098)\end{array}$ \\
\hline & $\begin{array}{l}2.504^{*} \\
(1.031) \\
1.710 \\
(.965) \\
-1.733^{* * *} \\
(.473) \\
-.852 \\
(1.366) \\
-.037 \\
(2.441) \\
1.801 \\
(3.052) \\
-5.509 \\
(3.074) \\
.023 \\
(.105) \\
-.749 \\
(.481) \\
-3.027 \\
(3.081) \\
.580 \\
(.564)\end{array}$ & $\begin{array}{l}2.026^{*} \\
(1.030) \\
1.605 \\
(.955) \\
-1.920^{* * *} \\
(.453) \\
-.216 \\
(1.390) \\
.736 \\
(2.288) \\
2.736 \\
(3.011) \\
-5.194 \\
(2.895) \\
-.031 \\
(.102) \\
-.618 \\
(.518) \\
-2.357 \\
(3.038) \\
.422 \\
(.558)\end{array}$ & $\begin{array}{l}1.424 \\
(1.033) \\
1.653 \\
(.929) \\
-1.219^{* *} \\
(.448) \\
.730 \\
(1.408) \\
.829 \\
(2.407) \\
2.922 \\
(2.924) \\
-5.136 \\
(2.902) \\
-.063 \\
(.102) \\
-.659 \\
(.502) \\
-2.245 \\
(2.803) \\
.478 \\
(.549)\end{array}$ & $\begin{array}{l}1.208 \\
(1.036) \\
1.558 \\
(.926) \\
-1.430^{* * *} \\
(.439) \\
.971 \\
(1.423) \\
1.279 \\
(2.291) \\
3.417 \\
(2.883) \\
-4.807 \\
(2.749) \\
-.097 \\
(.101) \\
-.577 \\
(.514) \\
-1.757 \\
(2.845) \\
.378 \\
(.548)\end{array}$ \\
\hline & & $\begin{array}{l}\text { Breastfeeding } \\
1.687 \\
(1.721) \\
2.753 \\
(1.643) \\
6.826^{* * *} \\
(1.488)\end{array}$ & & $\begin{array}{l}.503 \\
(1.551) \\
.984 \\
(1.473) \\
4.885^{* * *} \\
(1.338)\end{array}$ \\
\hline
\end{tabular}

Educational Environment in the Home

\begin{tabular}{|c|c|c|c|c|}
\hline & & & & \\
\hline & & & $1.899^{* *}$ & $1.820^{* *}$ \\
\hline & & & $(.622)$ & (.619) \\
\hline & & & $1.324^{* * *}$ & $1.054^{*}$ \\
\hline & & & $(.497)$ & $(.503)$ \\
\hline & & & .219 & .245 \\
\hline & & & $(.253)$ & $(.249)$ \\
\hline & & & $-8.713^{* * *}$ & $-7.815^{* *}$ \\
\hline & & & $(2.625)$ & $(2.554)$ \\
\hline & & & $-4.736^{* * *}$ & $-4.202^{* * *}$ \\
\hline & & & $(1.344)$ & $(1.356)$ \\
\hline & & & -2.412 & -2.223 \\
\hline & & & (1.409) & (1.387) \\
\hline & & & -2.985 & -2.521 \\
\hline & & & $(3.222)$ & $(3.415)$ \\
\hline $104.377^{* * * *}$ & $101.970^{* * * *}$ & $100.3915^{\text {**** }}$ & $94.065^{\text {**** }}$ & $93.890^{* * * *}$ \\
\hline$(0.588)$ & $(4.260)$ & $(4.419)$ & $(6.069)$ & $(6.170)$ \\
\hline 0.054 & 0.086 & 0.113 & 0.131 & .148 \\
\hline
\end{tabular}


extremely small amount, although the $\mathrm{R}^{2}$ does increase from $8.6 \%$ to $11.3 \%$ with the breastfeeding variables. This indicates that breastfeeding for a long duration is positively associated with higher PPVT scores, but because there are not significant differences between the poor/near-poor groups in their breastfeeding rates, breastfeeding has little impact on the coefficients for being poor or near-poor.

Model four incorporates the measures assessing whether a rich educational environment in the home is positively linked to cognitive skills. In this model, the poor/non-poor gap is reduced by 1.786 points and the $\mathrm{R}^{2}$ increases to $13.1 \%$. Specifically, for each additional educational activity that a child is involved in, their cognitive skills increase by 1.899 points. Additionally, for each additional unit of reading, cognitive skills go up by 1.324 points. Positive parenting does not have a statistically significant impact on cognitive skills. Educational levels appear to have the biggest impact, particularly when comparing those without a high school diploma to those with a postsecondary degree, as the former scored 8.713 points lower than the latter. Those with a high school diploma scored 4.736 points lower than those with a postsecondary degree. There were not significant differences between those with some postsecondary or "other" education and those with a postsecondary degree.

Finally, from Model 5 with the inclusion of all of the variables we see that the poverty gaps are slightly larger than they were in Model 4, but they are much smaller than in Models 1-3. With all of the controls, poor children score 5.437 points less and near-poor score 3.693 points less than the non-poor. Because both the breastfeeding and the educational environment variables shrink when included in the same model together, there is evidence that these variables are correlated with each other. However, because the poverty gap is smaller in Model 4 (with just the educational variables and not the breastfeeding variables) than in Model 3 (with just the breastfeeding variables and not the educational variables), the educational variables have a larger impact on the poverty gap than do the breastfeeding variables, despite the fact that breastfeeding for a long duration continues to have a strong positive impact on cognitive skills. However, the fact that a significant poverty gap remains while controlling for both breastfeeding and educational environments, indicates that the impact of poverty on cognitive skills goes beyond these two factors. Additionally, the $\mathrm{R}^{2}$ in this model increases only to $14.8 \%$ further indicating that the variance in cognitive skills overall are explained in large part by factors other than those included in these models. 


\section{Discussion}

Based on these results we see more support for the spurious effect argument than for the breastfeeding advocate argument, likely because there were no statistically significant differences in the rates of breastfeeding between the three economic groups. Breastfeeding is positively associated with PPVT scores, but insufficient to remediate the substantial impact of poverty on children's cognitive abilities in Canada. Providing an educationally rich environment shrinks the poverty gaps to a larger extent than does breastfeeding. Nonetheless, even with these interventions a significant poverty gap remains.

These results are important for shaping policy responses to educational inequities. Policies to increase breastfeeding rates may increase overall cognitive skills among Canadian children, but will not reduce inequalities. Such policies need to be created carefully so as not to expand economic inequality further. Recent research has indicated a negative impact on mothers' earnings of breastfeeding for a long duration (Rippeyoung and Noonan 2012), which could mean that increasing long duration breastfeeding rates have an unintended negative impact on household income. Thus, policies need to look holistically at the many interconnected ways in which educational inequalities can be addressed.

Despite these contributions, there are a few caveats to this analysis. First is that this analysis does not include a measure of exclusivity of breastfeeding (i.e., were the children breastfed exclusively or were they supplemented with formula). This is important as some argue that breastfeeding is "dose dependent," or that the more breastfeeding the better the outcomes (Oddy et al. 2003). If the dosage is what matters, breastfeeding a child longer would arguably provide more breast milk than a child who is breastfed for one month. Exclusivity was not incorporated into this analysis, as this was not measured in this survey and there are no other recent longitudinal surveys generalizable to the Canadian population that measure both breastfeeding and cognitive skills.

Another caveat is that mother's or PMK's cognitive skills were not included in the analyses, because they were not measured in these data. Mother's cognitive skills have been shown to have significant impacts on both children's cognitive skills and breastfeeding rates. Were this item included we might find no effect of breastfeeding on the PPVT overall, as has been found in other past research (Der et al. 2006; Gibson-Davis and Brooks-Gunn 2006; Jacobson et al. 1999), and this might also reduce the effect of poverty on cognitive skills, as Mayer (1997) found that studies that control for mother's cognitive skills show a smaller income gap in test scores. 
To address these caveats, more longitudinal data is needed to measure breastfeeding in more nuanced ways, including exclusivity, and also assess the mother's cognitive skills. Such data at the population level is difficult to come by but is essential for addressing these cognitive skills gaps which are related to a host of social problems.

\section{Conclusion}

Overall, there is evidence that an educationally rich home environment is more important than breastfeeding in reducing poverty based test score gaps. What is also clear from this analysis is that the effect of poverty cannot be fully explained by either of these factors, and the mechanism driving the poverty gap has yet to be explained fully.

The implication of this research should not be that breastfeeding should not be supported. There are a variety of ways in which breastfeeding has been shown to have a positive impact on mothers and children (for a review, see Health Canada 2005). As Bernice Hausman (2003) argues, regardless of any benefits of the practice, lactation is something that women's bodies do and to deny them their ability to do so denies women full autonomy over their bodies and leads to other forms of gender inequality.

What does seem clear is that breastfeeding promotion is an insufficient policy recommendation for addressing childhood poverty. Ruth Lawrence (2007:194) ends her editorial by writing that "[b]reastfeeding is the most precious gift a mother can give her infant. If there is illness or infection it may be a life saving gift. If there is poverty it may be the only gift." Based on the results of this analysis, poor mothers have gifts in addition to breastfeeding to offer their children, such as reading to them, taking them to the library, or attaining a postsecondary degree, that will help to reduce economic inequities related to child cognitive skills. However, we also see that despite these potential gifts, poverty remains a large predictor of cognitive skills gaps. Therefore, addressing the outcomes of childhood poverty will likely require a comprehensive approach that does not rely primarily on individuals, or rather, on one breastfed baby at a time.

\section{REFERENCES}

Anderson, James W., Bryan M. Johnstone, and Daniel T. Remley. 1999. Breastfeeding and cognitive development: A meta-analysis. American Journal of Clinical Nutrition 70:525-535. 
Brion, Marie-Jo A., Debbie A. Lawlor, Alicia Matijasevich, Bernardo Horta, Luciana Anselmi, Cora L. Araújo, Ana Maria B. Menezes, Cesar G. Victora, and George Davey Smith. 2011. What are the causal effects of breastfeeding on IQ, obesity and blood pressure? Evidence from comparing high-income with middle-income cohorts. International Journal of Epidemiology 40:670-680.

Chalmers, B., C. Levitt, M. Heaman, B. O'Brien, R. Sauve, and J. Kaczorowski. 2009. Breastfeeding rates and hospital breastfeeding practices in Canada: A national survey of women. Birth 36:122-132.

Conger, Rand D., Katherine J. Conger, and Monica J. Martin. 2010. Socioeconomic status, family processes, and individual development. Journal of Marriage and the Family 72:685-704.

Der, Geoff, G. David Batty, and Ian J. Deary. 2006. Effect of breast feeding on intelligence in children: Prospective study, sibling pairs analysis, and meta-analysis. BMJ 333(7575):945-948.

Dezoete, J. Anne, Barton A. MacArthur, and Bryan Tuck. 2003. Prediction of Bayley and Stanford-Binet scores with a group of very low birthweight children. Child: Care, Health \& Development 29(5):367-372.

Dickens, William T. 2005. Genetic differences and school readiness. The Future of Children 15(1):55-69.

Dubois, Lise and Manon Girard. 2003. Social inequalities in infant feeding during the first year of life: The longitudinal study of child development in Québec (LSCDQ 1998-2002). Public Health Nutrition 6(8):773-783

Gershoff, Elizabeth T., J. Lawrence Aber, C. Cybele Raver, and Mary Clare Lennon. 2007. Income is not enough: Incorporating material hardship into models of income associations with parenting and child development. Child Development 78(1):70-95.

Gibson-Davis, Christina M. and Jeanne Brooks-Gunn. 2006. Breastfeeding and verbal ability of 3-year-olds in a multicity sample. Pediatrics 118(5):e1444-e1451.

Gómez-Sanchiz, Manuela, Ramón Cañette, Immaculada Rodero, J. Enrique Baeza, and J. Antonio González. 2004. Influence of breast-feeding and parental intelligence on cognitive development in the 24-month-old child. Clinical Pediatrics 43:753-761.

Guo, Guang and Kathleen Mullan Harris. 2000. The mechanisms mediating the effects of poverty on children's intellectual development. Demography 37(4):431-447.

Haskins, Ron and Cecilia Rouse. 2005. Closing achievement gaps. The Future of Children 15(1):1-7.

Hausman, Bernice L. 2003. Mother's milk: Breastfeeding controversies in American culture. New York: Routledge. 
Health Canada. 2005. Nutrition for Healthy Term Infants - Statement of the Joint Working Group: Canadian Paediatric Society, Dietitians of Canada and Health Canada. Ottawa, ON: Minister of Public Works and Government Services. Retrieved 23 August 2011 from http://www.hc-sc.gc.ca/fn-an/ pubs/infant-nourrisson/nut infant nourrisson term-eng.php.

Jacobson, Sandra W., Lisa M. Chiodo, and Joseph L. Jacobson. 1999. Breastfeeding effects on intelligence quotient in 4- and 11-year-old children. Pediatrics 103:e71-76.

Janus, Magdalena and Eric Duku. 2007. The school entry gap: Socioeconomic family, and health factors associated with children's school readiness to learn. Early Education and Development 18(3):375-403.

Kiernan, Kathleen E. and M. Carmen Huerta. 2008 Economic deprivation, maternal depression, parenting and children's cognitive and emotional development in early childhood. The British Journal of Sociology 59:783-806.

Kimbro, Rachel Tolbert. 2006. On-the-job moms: Work and breastfeeding initiation and duration for a sample of low-income women. Maternal and Child Health Journal 10(1):19-26.

Kramer, Michael S., Frances Aboud, Elena Mironova, Irina Vanilovich, Robert W. Platt, Lidia Matush, Sergei Igumnov, Eric Fombonne, Natalia Bogdanovich, Thierry Ducruet, Jean-Paul Collet, Beverly Chalmers, Ellen Hodnett, Sergei Davidovsky, Oleg Skugarevsky, Oleg Trofimovich, Ludmila Kozlova, and Stanley Shapiro (PROBIT Study Group). 2008. Breastfeeding and child cognitive development. Archives of General Psychiatry 65(5):578-584.

La Leche League International (LLLI). 2007. IQ. Retrieved 18 August 2011 from http://www.llli.org/cbi/iq.html.

Lawrence, Ruth. 2007. The eradication of poverty one child at a time through breastfeeding. Breastfeeding Medicine 2(4):193-194.

Lugo-Gil, Julieta and Catherine S. Tamis-LeMonda. 2008. Family resources and parenting quality: Links to children's cognitive development across the first 3 years. Child Development 79(4):1065-1085.

Mason, Gladys and Sarah Roholt. 2006. Promoting, Protecting and Supporting Breastfeeding: A North Carolina Blueprint for Action. Raleigh, NC: North Carolina Division of Public Health. Retrieved 18 August 2011 from http://www.nutritionnc.com/breastfeeding/PDFS/bf-stateplanFINAL.pdf.

Massachusetts Breastfeeding Coalition. 2006. Study on Breastfeeding and Intelligence Flawed. Retrieved 27 April 2012 from http://massbreastfeeding. org/news/.

Mayer, Susan E. 1997. What Money Can't Buy: Family Income and Children's Life Chances. Cambridge, MA: Harvard University Press. 
Mortensen, Erik Lykke, Kim Fleischer Michaelsen, Stephanie A. Sanders, and June Machover Reinisch. 2002. The association between duration of breastfeeding and adult intelligence. Journal of the American Medical Association 287(18):2365-2946.

Oddy, Wendy H., Garth E. Kendall, Eve Blair, Nicholas H. de Klerk, Fiona J. Stanley, Louis I. Landau, S. Silburn, and Stephen Zubrick. 2003. Breast feeding and cognitive development in childhood: A prospective birth cohort study. Paediatric and Perinatal Epidemiology 17:81-90.

Phipps, Shelley and Lori Curtis. 2000. Poverty and Child Well-Being in Canada and the United States: Does it Matter How We Measure Poverty? Working Paper Series. Human Resources Development Canada (SP-55601-03E). Retrieved 18 August 2011 from http://publications.gc.ca/collections/Collection/RH63-1-556-01-03E.pdf.

Public Health Agency of Canada. 2009. 10 great reasons to breastfeed your baby. Retrieved 23 August 2011 from: http://www.phac-aspc.gc.ca/hp-ps/dcadea/stages-etapes/childhood-enfance $0-2 /$ nutrition/reasons-raisons-eng. php.

Rippeyoung, Phyllis L.F. 2009. Feeding the state: Breastfeeding and women's well-being in context. Journal of the Association for Research on Mothering 11(1):36-48.

Rippeyoung, Phyllis L.F. and Mary C. Noonan. 2012. Is breastfeeding truly cost free? Income consequences of breastfeeding for women. American Sociological Review 77:244-267.

Smith, Judith R., Jeanne Brooks-Gunn, and Pamela K. Klebanov. 1997. Consequences of living in poverty for young children's cognitive and verbal ability and early school achievement. Pp. 132-189 in G.J. Duncan and J. Brooks-Gunn, eds., Consequences of Growing Up Poor. New York: Russell Sage Foundation.

Statistics Canada. 2006. National Longitudinal Survey of Children and Youth (NLSCY): Detailed Information for 2004-2005 (Cycle 6). Downloaded 1 May 2012 from http://www23.statcan.gc.ca:81/imdb/p2SV.pl?Function $=$ getSurvey $\&$ SurvId $=4450 \&$ SurvVer $=1 \&$ InstaId $=16044 \&$ InstaVer $=6 \& S$ DDS $=4450 \&$ lang $=$ en $\& \mathrm{db}=$ imdb $\& a d m=8 \&$ dis $=2$.

2008. Peabody Picture Vocabulary Test-Revised. Downloaded 19 August 2011 from http://www.statcan.gc.ca/pub/81-004-x/def/4153358eng.htm.

UNICEF. 2011. The Baby Friendly Hospital Initiative. Downloaded on $31 \mathrm{Au}-$ gust 2011 from http://www.unicef.org/programme/breastfeeding/baby. $\underline{\mathrm{htm}}$.

Wolf, Joan. 2010. Is Breast Best? Taking on the Breastfeeding Experts and the New High Stakes of Motherhood. New York: NYU Press.

World Health Organization. 2003. Global Strategy for Infant and Young Child Feeding. Geneva, Switzerland: World Health Organization. 
Yeung, W. Jean, Miriam R. Linver, and Jeanne Brooks-Gunn. 2002. How money matters for young children's development: Parental investment and family processes. Child Development 73:1861-1879.

Zhou, Shao J., Peter Baghurst, Robert A. Gibson, and Maria Makrides. 2007. Home environment, not duration of breast-Feeding, predicts intelligence quotient of children at four years. Nutrition 23(3):236-241.

Phyllis L.F. Rippeyoung, Ph.D. is an Associate Professor of Sociology at the University of Ottawa, having previously taught courses in research methods, statistics, social stratification, work, and gender, as an assistant professor at Acadia University. Her research has examined inequality in early childhood and gender inequality in pay, the workplace and in families. Her current research examines how infant feeding practices shape and are shaped by inequities of gender, class, and sexual orientation.

Phyllis.Rippeyoung@uottawa.ca 
